\title{
The Breakdown Pressure Calculating Model for Open Hole Completion CBM Well Hydraulic Fracturing
}

\author{
Li Yuwei ${ }^{1}$, Ai Chi ${ }^{*}, 1$, Liu Yu², Gao Changlong ${ }^{1}$ \\ ${ }^{I}$ Northeast Petroleum University, College of Petroleum Engineering, Daqing, Heilongjiang, 163318, China \\ ${ }^{2}$ Research Institute of Petroleum Engineering, Dagang Oilfield, Tianjin, 300280, China
}

\begin{abstract}
The open hole completion CBM borehole wall intersects with the weak surface such as cleats and fractures. In the process of hydraulic fracturing, the fractures may origin from coal body or cleats, which makes the rupture mechanism and rupture models of the borehole wall being different from the conventional reservoirs. The previous model for calculating breakdown pressure of open hole completion borehole wall considering tension failure has poor applicability for calculating breakdown pressure. Considering the spatial relationship of the intersection of borehole wall and cleats, analyzing the stress state of borehole wall rock and cleats wall, and basing on elastic mechanics and fracture mechanics, the breakdown pressure calculation model for CBM open hole completion hydraulic fracturing was established. In the model, fractures initiate from coal rock body, tensile failure along with face cleats, shear failure along with face cleats, tensile failure along with butt cleats and shear failure along with butt cleats five kinds of damage modes were considered. According to example calculation, the breakdown pressure of HX-L1 well calculated using the model is $14.81 \mathrm{MPa}$. The actual pressure obtained by bottom hole pressure gage is $15.42 \mathrm{MPa}$, and the relative error is $3.96 \%$. The calculated result agrees with the actual conditions. It can be concluded that the model can be used to calculate the breakdown pressure for open hole completion CBM well hydraulic fracture.
\end{abstract}

Keywords: Breakdown pressure, CBM well, hydraulic fracturing, open hole completion.

\section{INTRODUCTION}

Coalbed methane reservoirs have the character of low porosity and low permeability, and mostly must be reconstructed if we want to achieve the goal of industrialized development. Hydraulic fracturing is one of the important techniques to achieve effective development of coalbed methane and it has been widely used worldwide in recent years. The accurate calculation of breakdown pressure is the important prerequisite for the successful implementation of hydraulic fracturing. It has become a research hotspot and difficulty of CBM hydraulic fracturing. Nowadays the study of breakdown pressure in sandstone is mainly based on the tensile failure criterion in elasticity, and the relative calculation model was based on the premise of homogeneous formation [1-4]. For the fractured reservoir, Yan Jin and Mian Chen $[5,6]$ took the influence of reservoir fractures on breakdown pressure of open hole well into consideration and established the relative calculation model. Jinzhou Zhao and Lan Ren [7-9] established the breakdown pressure calculation model of fractured reservoir under the condition of perforated completion, and analyzed the influence of different initiation patterns on initiation pressure. For the calculation of breakdown pressure of coal seams, mainly referred to the existed sandstone reservoir breakdown pressure calculation model, or simulating using finite element program [10], and there was not a relatively perfect

*Address correspondence to this author at the College of Petroleum Engineering, Northeast Petroleum University, Daqing 163318, Heilongiiang province, China; Tel: 0086-459-6503073; E-mail: liyuweibox@126.com theory to analyze the influence of cleats and fractures on the breakdown pressure. In this paper, considering the differences between coal body and face cleats, butt cleats in mechanical properties, the model for calculating breakdown pressure in open hole completion coalbed was established by analyzing the spatial relationship between bare hole wall and cleats, which can be used to determine the breakdown patterns and calculate the breakdown pressure. It can provide a new method for calculating the breakdown pressure in coalbed fracturing.

\section{THE BOREHOLE ROCK MECHANICAL MODEL FOR OPEN HOLE COMPLETION}

In order to analyze the stress state around the vertical borehole in coalbed, the two-dimension mechanical model of the borehole wall was established, which could be shown in Fig. (1). The borehole wall rock is subjected to horizontal maximum principal stress $\sigma_{\mathrm{H}}$, horizontal minimum principal stress $\sigma_{\mathrm{h}}$ and the pressure of fluid $\left(p_{\mathrm{w}}\right)$ in the borehole after the borehole is opened.

In order to analyze and calculate the value of stress around open hole borehole, making the following assumptions:

(1) The coalbed is uniform isotropic before breaking up in fracturing;

(2) Ignore the effect of coalbed plasticity before breaking up, considering that the coalbed is linear elastic porous medium; 
(3) Ignore the influence of physical and chemical effects between fracturing fluid and coalbed;

(4) Ignore the effects of additional thermal stress caused by the temperature difference between fracturing fluid and borehole wall rock, because the coalbed methane wells are usually shallow.

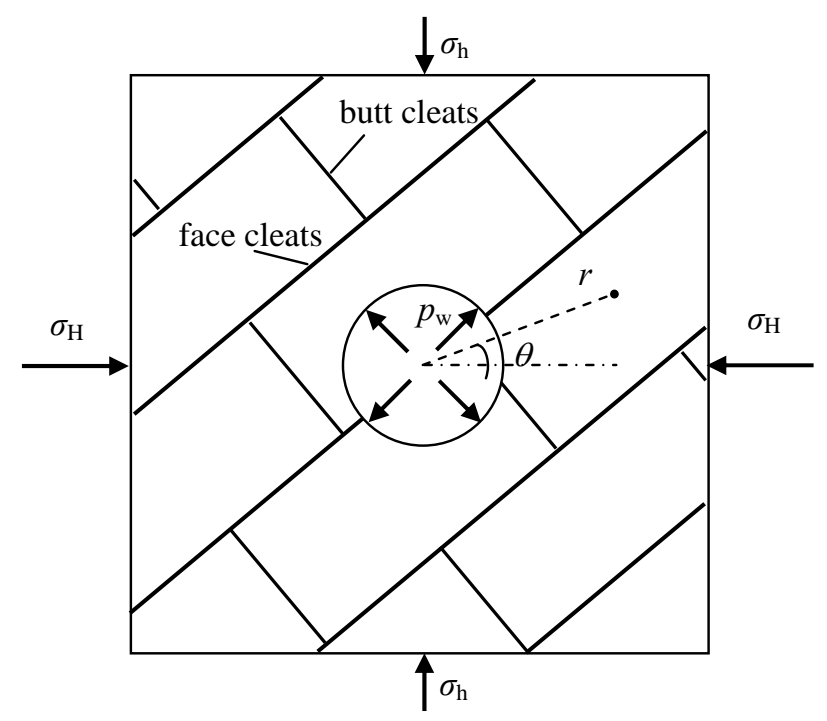

Fig. (1). The mechanical model of borehole rock for open hole completion well.

\section{THE STRESS DISTRIBUTION MODEL AROUND THE BOREHOLE FOR OPEN HOLE COMPLETION}

Under the effect of maximum principal stress, minimum principal stress, vertical stress, fracturing fluid pressure and the filtration effect of fracturing fluid, there is stress concentration phenomenon at the wellbore area. Assuming that tensile stress is negative, compressive stress is positive, and the stress distribution can be expressed as follow [11].

$$
\left\{\begin{aligned}
\sigma_{r}= & \frac{r_{w}^{2}}{r^{2}} p_{w}+\frac{1}{2}\left(\sigma_{H}+\sigma_{h}\right)\left(1-\frac{r_{w}^{2}}{r^{2}}\right)+\frac{1}{2}\left(\sigma_{H}-\sigma_{h}\right)\left(1+\frac{3 r_{w}^{4}}{r^{4}}-\frac{4 r_{w}^{2}}{r^{2}}\right) \cos 2 \theta \\
& +\left[\frac{\alpha(1-2 \mu)}{2(1-\mu)}\left(1-\frac{r_{w}^{2}}{r^{2}}\right)-\phi\right]\left(p_{w}-p_{p}\right) \\
\sigma_{\theta}= & -\frac{r_{w}^{2}}{r^{2}} p_{w}+\frac{1}{2}\left(\sigma_{H}+\sigma_{h}\right)\left(1+\frac{r_{w}^{2}}{r^{2}}\right)-\frac{1}{2}\left(\sigma_{H}-\sigma_{h}\right)\left(1+\frac{3 r_{w}^{4}}{r^{4}}\right) \cos 2 \theta \\
& +\left[\frac{\alpha(1-2 \mu)}{2(1-\mu)}\left(1+\frac{r_{w}^{2}}{r^{2}}\right)-\phi\right]\left(p_{w}-p_{p}\right) \\
\sigma_{z}= & \sigma_{v}-2 \mu\left(\sigma_{H}-\sigma_{h}\right) \frac{r_{w}^{2}}{r^{2}} \cos 2 \theta+\left[\frac{\alpha(1-2 \mu)}{1-\mu}-\phi\right]\left(p_{w}-p_{p}\right) \\
\tau_{r \theta}= & -\frac{1}{2}\left(\sigma_{H}-\sigma_{h}\right)\left(1-\frac{3 r_{w}^{4}}{r^{4}}+\frac{2 r_{w}^{2}}{r^{2}}\right) \sin 2 \theta \\
\tau_{\theta z}= & \tau_{r z}=0
\end{aligned}\right.
$$

where: $\sigma_{\mathrm{r}}$ is the radial stress in borehole area of the coalbed, $\mathrm{MPa} ; \sigma_{\theta}$ is circumferential stress, $\mathrm{MPa} ; \sigma_{\mathrm{z}}$ is the vertical stress, MPa; $\tau_{\mathrm{r} \theta} 、 \tau_{\theta \mathrm{z}}$ and $\tau_{\mathrm{rz}}$ are the shear stresss, MPa; $\sigma_{\mathrm{H}}$ is maximum principal stress; $\sigma_{\mathrm{h}}$ is minimum principal stress, $\mathrm{MPa} ; \sigma_{\mathrm{v}}$ is the overburden stress, MPa; $r$ is the wellbore polar radius at any point, $\mathrm{m} ; r_{\mathrm{w}}$ is the radius of wellbore, $\mathrm{m} ; \mu$ is Poisson's ratio, dimensionless variable; $p_{\mathrm{w}}$ is the fluid pressure in the wellbore, $\mathrm{MPa} ; \theta$ is the sinistral polar angle between radial direction of at point and maximum principal stress, $\left(^{\circ}\right) ; \alpha$ is Biot coefficient; $\phi$ is the porosity of the coalbed.

Especially, when $r=r_{\mathrm{w}}$, the stress distribution on the borehole wall can be expressed as follow.

$$
\left\{\begin{array}{l}
\sigma_{r}=p_{w}-\phi\left(p_{w}-p_{p}\right) \\
\sigma_{\theta}=-p_{w}+\left(\sigma_{H}+\sigma_{h}\right)-2\left(\sigma_{H}-\sigma_{h}\right) \cos 2 \theta+\left[\frac{\alpha(1-2 \mu)}{1-\mu}-\phi\right]\left(p_{w}-p_{p}\right) \\
\sigma_{z}=\sigma_{v}-2 \mu\left(\sigma_{H}-\sigma_{h}\right) \cos 2 \theta+\left[\frac{\alpha(1-2 \mu)}{1-\mu}-\phi\right]\left(p_{w}-p_{p}\right) \\
\tau_{r \theta}=0 \\
\tau_{\theta z}=\tau_{r z}=0
\end{array}\right.
$$

After identified the stress distribution of borehole wall for open hole completion, analyzing the stress of coal body and cleats in the process of fracturing, according to the failure criterion, the breakdown pressure calculation model can be established.

\section{BREAKDOWN PRESSURE CALCULATION MODEL FOR OPEN HOLE COMPLETION IN HYDRAULIC FRACTURING}

Under the conditions of open hole completion, the borehole may intersect with face cleats and butt cleats (as is shown in Fig. 1). The existence of cleats can affect the breakdown position of the fractures and the value of breakdown pressure. The breakdown pressure calculation models that the fractures generated from coal body and cleats for open hole completion are established according to the stress state of the borehole and coalbed cleats using fracturing mechanics theory.

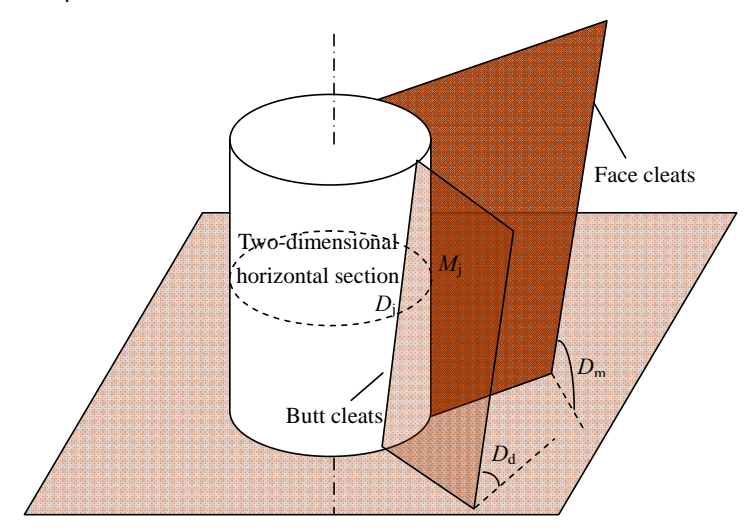

Fig. (2). The borehole intersecting with cleats.

The intersection condition between borehole and cleats could be shown in Fig. (2). It can be concluded that the shear stress on the borehole wall in all directions is 0 through formula (2), and the three principal stress on open hole wall can be shown as follow. 


$$
\left\{\begin{array}{l}
\sigma_{1}=\sigma_{r} \\
\sigma_{2}=\sigma_{z} \\
\sigma_{3}=\sigma_{\theta}
\end{array}\right.
$$

Under the effects of principal stress, the damage modes of the coalbed borehole wall have five kinds: fractures initiate from coal rock body, tensile failure along with face cleats, shear failure along with face cleats, tensile failure along with butt cleats and shear failure along with butt cleats. The damage models during fracturing must distinguished by analyzing the stress state of the rock.

\subsection{Fractures Initiating from Coal Rock Body}

The circumferential stress $\sigma_{\theta}$ is tensile stress during fracturing. According to the tension failure criterion based on fracture mechanics, the breakdown condition of the borehole wall can be expressed as follow.

$\sigma_{\theta}-\alpha p_{p} \leq-\sigma_{t}$

where: $\sigma_{\mathrm{t}}$ is tensile strength of the coal rock, $\mathrm{MPa}$.

It can be concluded from formula (4) that the breakdown of borehole wall is caused by the increasing of fluid column pressure in the borehole. When the circumferential stress of the coal body is greater than the tensile strength, the borehole wall becomes breakdown, and the damage model is tension failure. The initiation orientation is along with the direction where the value of circumstantial stress $\sigma_{\theta}$ is smallest, and the orientation angle is $0^{\circ}$ or $180^{\circ}$.

\subsection{Tension Failure Along with Face Cleats}

Firstly, the coordinate system established can be shown as follow. In the earth coordinates $(i, j, k)$, where, $i$ is the unit vector in the direction of geographical north $\mathrm{N} ; j$ is the unit vector in the direction of the geographic east $\mathrm{E} ; k$ is the unit vector in the opposite direction of the vertical center of the earth. The strike direction of face cleats is north by east $N_{\mathrm{m}}$ degrees; the horizontal inclination is $D_{\mathrm{m}}$ degrees. The strike direction of butt cleats is north by east $N_{\mathrm{d}}$ degrees and $N_{\mathrm{d}}-N_{\mathrm{m}}=\pi / 2$; the horizontal inclination is $D_{\mathrm{d}}$ degrees. The direction of maximum horizontal principal stress is north by east $H_{\mathrm{z}}$ degrees. The intersection point between twodimension horizontal cross section and the face cleats on borehole wall is $\mathrm{M}_{\mathrm{j}}$, whose orientation is north by east $N_{\mathrm{mj}}$ degrees. The intersection point between two-dimension horizontal cross section and the butt cleats on borehole wall is $\mathrm{D}_{\mathrm{j}}$, whose orientation is north by east $N_{\mathrm{dj}}$ degrees.

The directional vector of face cleats in the coordinate system can be expressed as follow.

$n_{\mathrm{m}}=\left[-\sin \left(D_{m}\right) \cos \left(N_{m}\right)\right] i+\left[\sin \left(D_{m}\right) \sin \left(N_{m}\right)\right] j+\cos \left(D_{m}\right) k$

The directional vector of principal stress $\sigma_{1}$ can be expressed as follow.

$n_{\mathrm{mz}}\left(\sigma_{1}\right)=\cos \left(N_{m j}\right) i+\sin \left(N_{m j}\right) j$
The directional vector of principal stress $\sigma_{2}$ can be expressed as follow.

$n_{\mathrm{mz}}\left(\sigma_{2}\right)=k$

The directional vector of principal stress $\sigma_{3}$ can be expressed as follow.

$n_{\mathrm{mz}}\left(\sigma_{3}\right)=-\sin \left(N_{m j}\right) i+\cos \left(N_{m j}\right) j$

The normal stress loading on the face cleats at the intersection point between face cleats and open hole wall can be expressed as follow.

$\sigma_{\mathrm{mn}}=\cos ^{2} \gamma_{\mathrm{m} 1} \sigma_{1}+\cos ^{2} \gamma_{\mathrm{m} 2} \sigma_{2}+\cos ^{2} \gamma_{\mathrm{m} 3} \sigma_{3}$

where: $\sigma_{\mathrm{mn}}$ is the normal stress loading on the face cleats, $\mathrm{MPa} ; \gamma_{\mathrm{mi}}$ is the included angle between the face normal line of face cleats and the $\mathrm{i}$-th principal stress, $\left(^{\circ}\right), i=1,2,3$.

According to the included angle formula between two vectors in elastic-plastic mechanics, the cosine value of $\gamma_{\mathrm{mi}}$ can be expressed as follows.

$\cos \gamma_{\mathrm{mi}}=\frac{n_{m} \cdot n_{m z}\left(\sigma_{i}\right)}{\left|n_{m}\right| \cdot\left|n_{m z}\left(\sigma_{i}\right)\right|}(i=1,2,3)$

By calculation, the expression of $\gamma_{\mathrm{mi}}$ can be obtained.

$\gamma_{\mathrm{m} 1}=\arccos \left|\begin{array}{l}-\sin \left(D_{m}\right) \cos \left(N_{m}\right) \cos \left(N_{m j}\right)+ \\ \sin \left(D_{m}\right) \sin \left(N_{m}\right) \sin \left(N_{m j}\right)\end{array}\right|$

$\gamma_{\mathrm{m} 2}=D_{m}$

$\gamma_{\mathrm{m} 3}=\arccos \left|\begin{array}{l}\sin \left(D_{m}\right) \cos \left(N_{m}\right) \sin \left(N_{m j}\right) \\ +\sin \left(D_{m}\right) \sin \left(N_{m}\right) \cos \left(N_{m j}\right.\end{array}\right|$

Because face cleats intersect with the borehole wall, the fluid pressure in the face cleats is equal to the fluid column pressure in the borehole. When the pressure is at or greater than the effective compression stress loading on the face cleats, it will occur tension failure along with face cleats, the breakdown criteria can be expressed as follow.

$p_{\mathrm{mzf}}-\alpha p_{p} \geq \sigma_{\mathrm{mn}}$

where: $p_{\mathrm{mzf}}$ is the fluid pressure in the fracture when the face cleats occur tension failure, $\mathrm{MPa}$.

\subsection{Shear Failure Along with Face Cleats}

Jaeger has established the model for calculating rock mass strength with fractures [12], and Yan Jin has used the model for calculating fractures initiating of vertical wells hydraulic fracturing in fractured formation [5]. The cleats in the coal rock can be seen as structural faces with weak mechanical properties.

When the shear stress loading on the face cleats is greater than the shear strength, it will occur shear failure along with face cleats, and the relationship can be shown as follow: 


$$
\sigma_{1}-\sigma_{3} \geq \frac{2\left(\tau_{\mathrm{m} 0}+\mu_{\mathrm{m}} \sigma_{3}\right)}{\left(1-\mu_{\mathrm{m}} \cot \gamma_{m 1}\right) \sin 2 \gamma_{m 1}}
$$

where: $\tau_{\mathrm{m} 0}$ is the adhesion of the coal body in face cleats, $\mathrm{MPa} ; \mu_{\mathrm{m}}$ is the internal friction coefficient in face cleats, dimensionless variable.

\subsection{Tension Failure Along with Butt Cleats}

The mechanics mechanism of tension failure along with butt cleats in hydraulic fracturing is similar to the tension failure along with face cleats. In earth coordinates, the direction vector of butt cleats can be expressed as follow.

$n_{\mathrm{d}}=\left[-\sin \left(D_{d}\right) \cos \left(N_{d}\right)\right] i+\left[\sin \left(D_{d}\right) \sin \left(N_{d}\right)\right] j+\cos \left(D_{d}\right) k$

Using coordinate transformation, the directional vector of principal stress $\sigma_{1}$ can be expressed as follow.

$n_{\mathrm{dz}}\left(\sigma_{1}\right)=\cos \left(N_{d j}\right) i+\sin \left(N_{d j}\right) j$

The directional vector of principal stress $\sigma_{2}$ can be expressed as follow.

$n_{\mathrm{dz}}\left(\sigma_{2}\right)=k$

The directional vector of principal stress $\sigma_{3}$ can be expressed as follow.

$n_{\mathrm{dz}}\left(\sigma_{3}\right)=-\sin \left(N_{d j}\right) i+\cos \left(N_{d j}\right) j$

According to formula (10), the cosine value of the included angle between the face normal line of butt cleats and each principal stress can be expressed as follow.

$\cos \gamma_{d i}=\frac{n_{d} \cdot n_{d z}\left(\sigma_{i}\right)}{\left|n_{d}\right| \cdot\left|n_{d z}\left(\sigma_{i}\right)\right|}(i=1,2,3)$

The normal stress loading on the butt cleats at the intersection point between butt cleats and open hole wall can be expressed as follow.

$\sigma_{\mathrm{dn}}=\cos ^{2} \gamma_{d 1} \sigma_{1}+\cos ^{2} \gamma_{d 2} \sigma_{2}+\cos ^{2} \gamma_{d 3} \sigma_{3}$

where: $\sigma_{\mathrm{dn}}$ is the normal stress loading on butt cleats, $\mathrm{MPa} ; \gamma_{d \mathrm{i}}$ is the included angle between the face normal line of butt cleats and the $\mathrm{i}$-th principal stress, $\left(^{\circ}\right), i=1,2,3$.

When the fluid pressure in butt cleats is at or greater than the effective compression stress loading on the butt cleats, it will occur tension failure along with butt cleats, the breakdown criteria can be expressed as follow.

$p_{\mathrm{dzf}}-\alpha p_{p} \geq \sigma_{\mathrm{dn}}$

where: $p_{\mathrm{dzf}}$ is the fluid pressure in the fracture when the butt cleats occur tension failure, MPa.

\subsection{Shear Failure Along with Butt Cleats}

The mechanics mechanism of shear failure along with butt cleats is similar to the shear failure along with face cleats (in 4.3). For the butt cleats, the relationship between the shear stress loading on butt cleats and shear strength should be particularly analyzed. The breakdown criteria can be expressed as follow.

$$
\sigma_{1}-\sigma_{3} \geq \frac{2\left(\tau_{\mathrm{d} 0}+\mu_{\mathrm{d}} \sigma_{3}\right)}{\left(1-\mu_{\mathrm{d}} \cot \gamma_{d 1}\right) \sin 2 \gamma_{d 1}}
$$

where: $\tau_{\mathrm{d} 0}$ is the adhesion of the coal body in butt cleats, $\mathrm{MPa} ; \mu_{\mathrm{d}}$ is the internal friction coefficient in butt cleats, dimensionless variable.

\subsection{The Determination of Breakdown Pressure}

For open hole completion hydraulic fracturing in coal bed, the breakdown pressure and breakdown models is the one that is most prone to damage in the five types of breakdown. The actual breakdown pressure is the minimum value of the five. The breakdown pressure of open hole completion hydraulic fracturing can be expressed as follow.

$$
p_{\mathrm{f}}=\min \left\{p_{b f}, p_{m z f}, p_{m i f}, p_{d z f}, p_{d j f}\right\}
$$

where: $p_{\mathrm{f}}$ is the breakdown pressure in open hole completion hydraulic fracturing, $\mathrm{MPa} ; p_{\mathrm{bf}}$ is the breakdown pressure when the failure origins from the coal body, $\mathrm{MPa} ; p_{\text {mjf }}$ is the breakdown pressure when the breakdown is caused by the shear failure along with face cleats, $\mathrm{MPa} ; p_{\text {djf }}$ is the breakdown pressure when the breakdown is caused by the shear failure along with butt cleats, MPa.

\section{EXAMPLE AND THE ANALYSIS OF AFFECTING FACTOR}

The CBM well using open hole completion is HX-L1 in south of Hegang mining area. The horizontal maximum principal stress in open hole interval is $12.29 \mathrm{MPa}$, and the orientation is north by east $72.32^{\circ}$. The horizontal minimum principal stress $10.14 \mathrm{MPa}$; the overburden stress is 12.56 $\mathrm{MPa}$; the pore pressure is $7.41 \mathrm{MPa}$ and the porosity is 0.05 ; the coefficient of effective stress is 0.9 ; the radius of the borehole is $0.1 \mathrm{~m}$. According to the logging and coring data, the strike direction of the face cleats is north by east $54^{\circ}$; the strike direction of the butt cleats is north by east $144^{\circ}$. The face and butt cleats have a larger inclination angle, and the average inclination angle of face cleats is $89^{\circ}$, and the face cleats is $84^{\circ}$. Determined by laboratory experiments, the mechanical parameters of coal body can be seen as follow. The Poisson's ratio is 0.31 ; Young's modulus is $3800 \mathrm{MPa}$; The tension strength of coal body is $0.76 \mathrm{MPa}$; the adhesion of the coal body in face cleats is $0.42 \mathrm{MPa}$; the internal friction coefficient is 0.3 ; the adhesion of the coal body in butt cleats is $0.57 \mathrm{MPa}$; the internal friction coefficient is 0.4 .

The breakdown pressure was calculated using the model. The breakdown pressure is $16.09 \mathrm{MPa}$ when the failure origins from the coal body. The breakdown pressure is 14.81 $\mathrm{MPa}$ when the breakdown is caused by tension failure along with face cleats, and the pressure is $16.24 \mathrm{MPa}$ when the breakdown is caused by shear failure. The breakdown pressure is $19.28 \mathrm{MPa}$ when the breakdown is caused by tension failure along with butt cleats, and the pressure is 25.22 $\mathrm{MPa}$ when the breakdown is caused by shear failure. It can be concluded that the breakdown model of the well is 


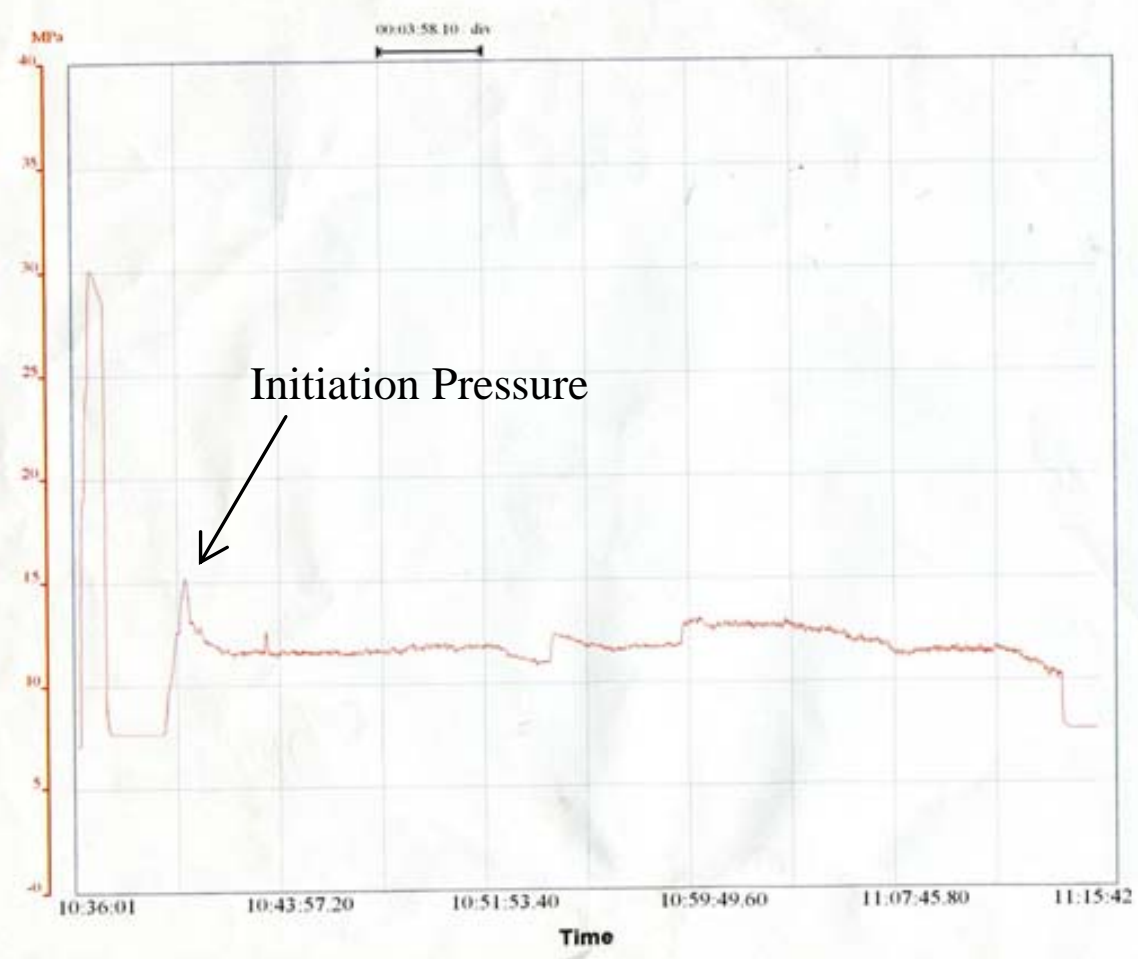

Fig. (3). The bottom hole pressure curve in the process of fracturing for HX-L1 well.

tension failure along with face cleats, and the breakdown pressure is $14.81 \mathrm{MPa}$. The actual field fracturing curve obtained by bottom hole pressure gage can be shown in Fig. (3). The breakdown pressure is $15.42 \mathrm{MPa}$, and it is close to the calculation result. The relative error is $3.96 \%$, and the error value is in the allowable range of engineering application. Co MPared the actual breakdown pressure with the calculated pressure, it can be concluded that the calculated result agrees with the actual conditions. The breakdown pressure calculating model for CBM open hole completion hydraulic fracturing has good applicability.

In order to determine the effects of different factors on breakdown pressure, the effects of cleats inclination angle, coal bed adhesion in the cleats and internal friction coefficient on the breakdown pressure was analyzed considering that the strike direction of cleats is certain.

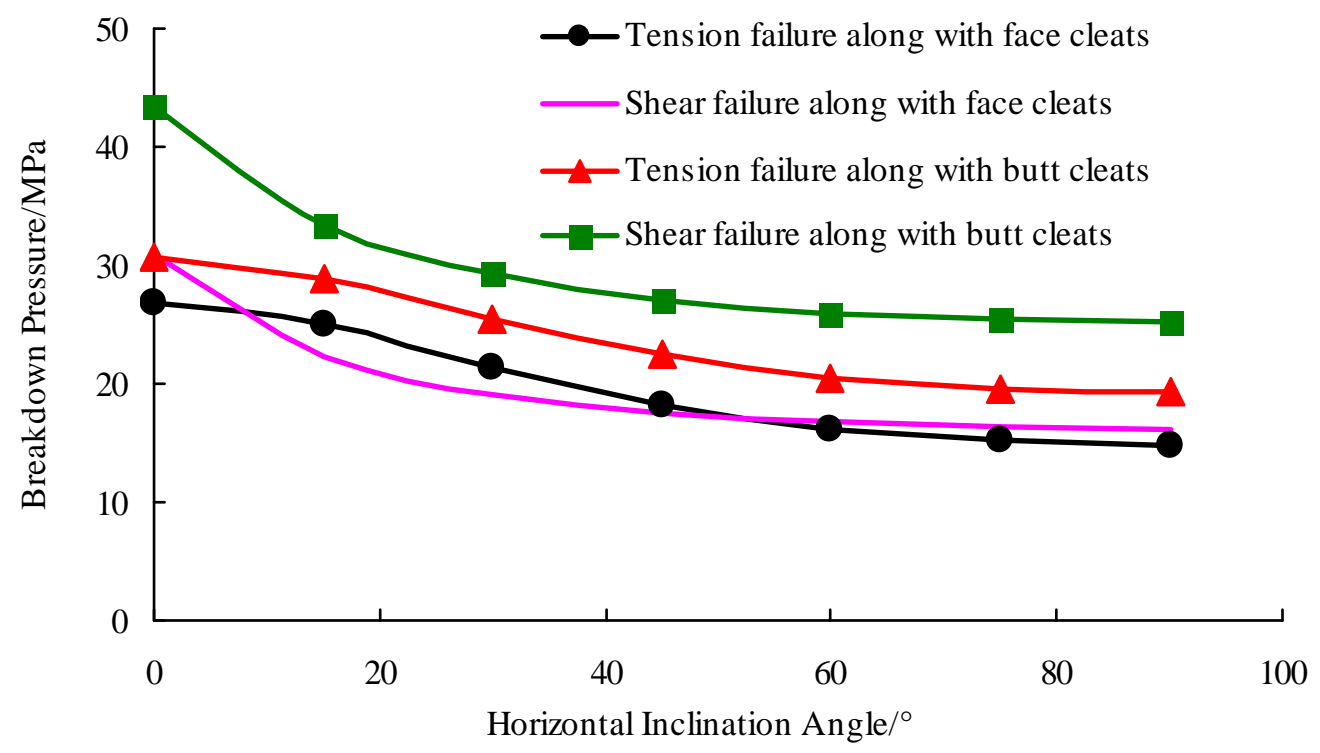

Fig. (4). The effects of cleats inclination angle on breakdown pressure. 


\subsection{The Effects of Cleats Inclination Angle on Breakdown Pressure}

As was shown in Fig. (4), it can be concluded that: with the increasing of horizontal inclination angle of the face and butt cleats, the breakdown pressure decreases, on the condition that the rupture is caused by tension failure and shear failure along with face cleats and butt cleats. When the horizontal inclination angle is $0^{\circ}$, the breakdown press becomes maximum. When the inclination angle of the cleats is greater than $75^{\circ}$, the breakdown pressures which are caused by tension and shear failure have little change.

\subsection{The Effects of Adhesion in the Cleats and Internal Friction Coefficient on Breakdown Pressure}

The change of adhesion in the cleats and internal friction coefficient has effects on the breakdown pressure caused by shear failure, so the breakdown pressure which is caused by shear failure along with face and butt cleats is drawn according to the calculation results.

As was shown in Figs. $(\mathbf{5}, \mathbf{6})$, with the increasing of adhesion in the cleats, the breakdown pressure increases, on the condition that the rupture is caused by shear failure along with face cleats and butt cleats, but the increasing rate is

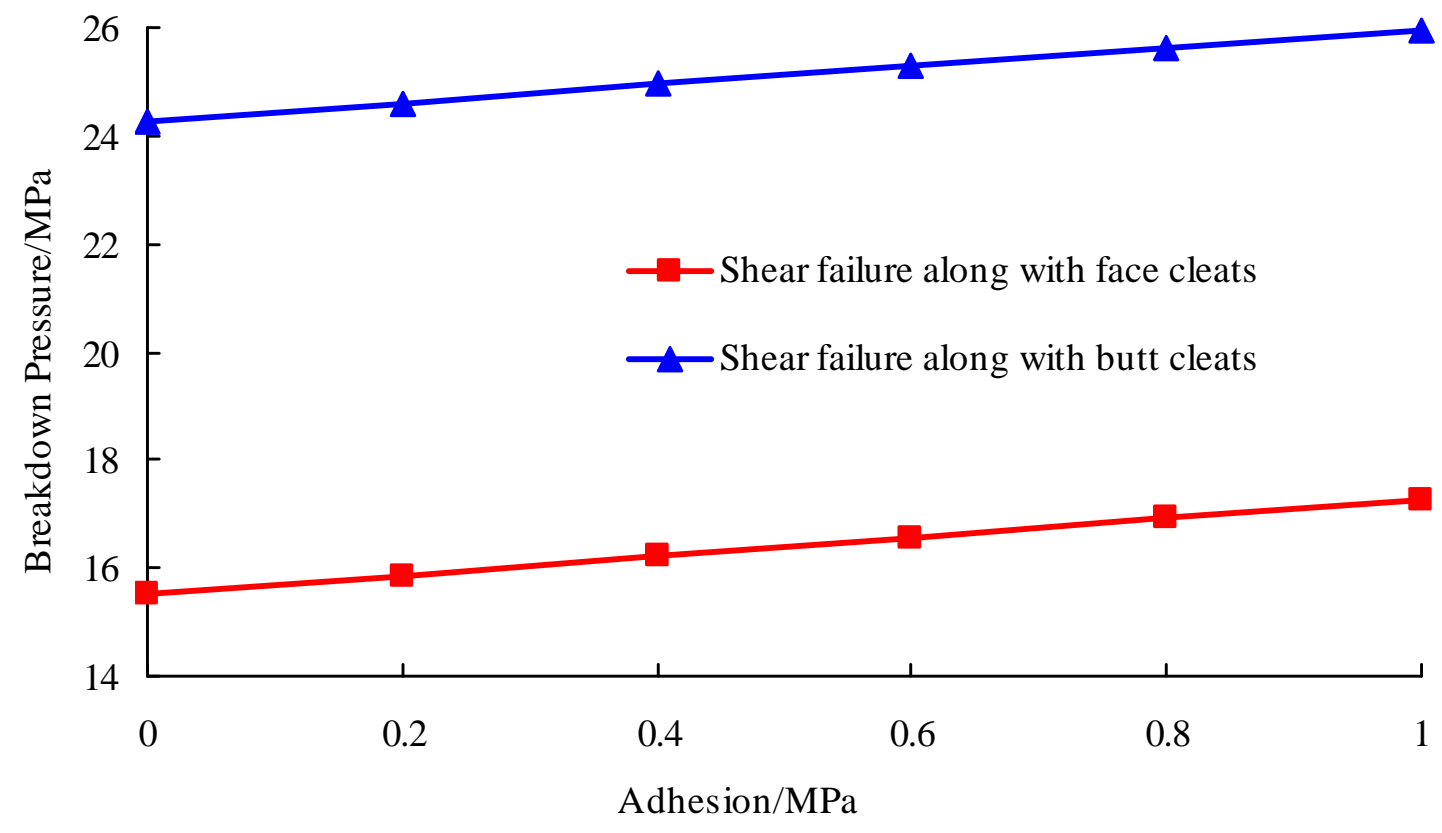

Fig. (5). The effects of adhesion in the cleats on breakdown pressure caused by shear failure.

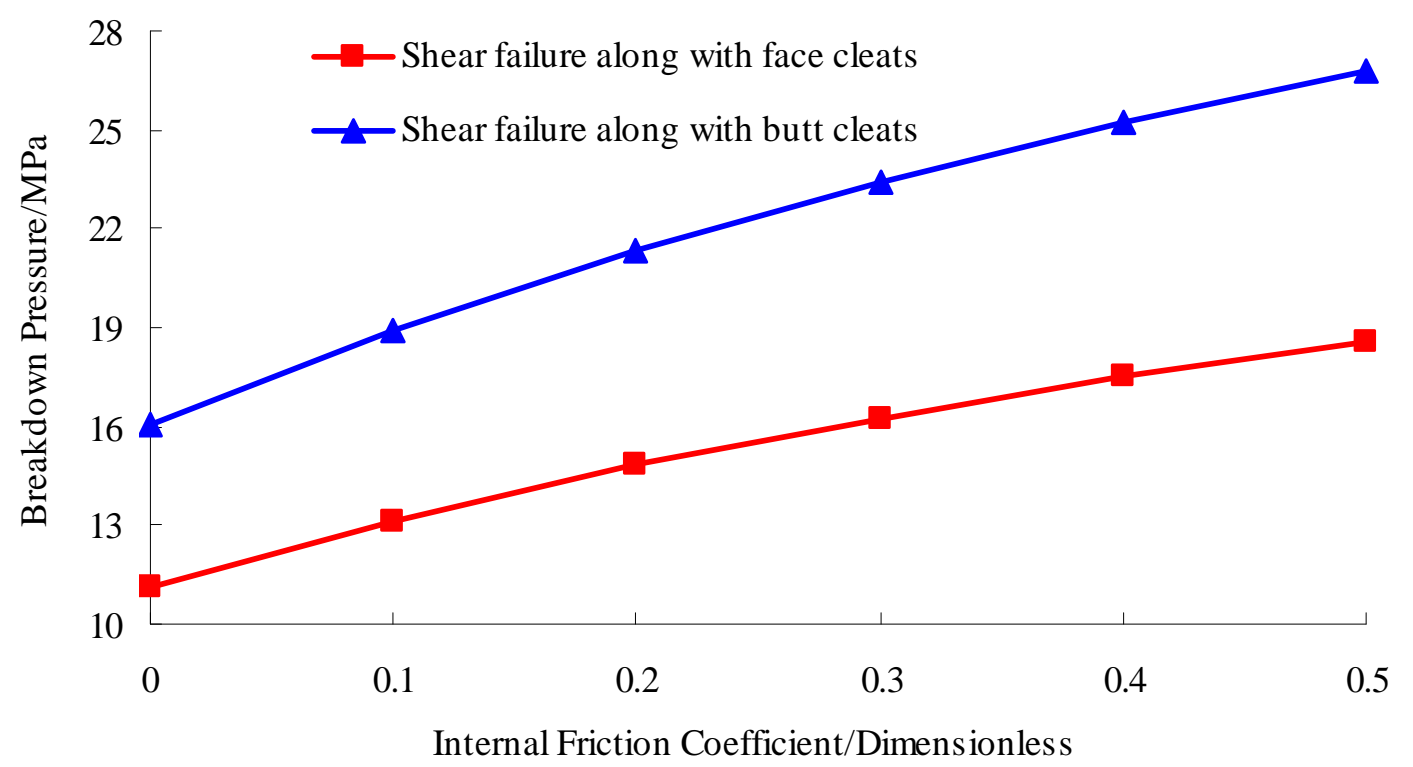

Fig. (6). The effects of internal friction coefficient of the cleats wall on breakdown pressure caused by shear failure. 
small, and it can be concluded that: the effects of adhesion on breakdown pressure is not significant. With the increasing of internal friction coefficient, the breakdown pressure increases significantly when the rupture is caused by shear failure, and it can be concluded that: the change of internal friction coefficient has great effects on breakdown pressure.

\section{CONCLUSION}

1. Considering the spatial relationship of the intersection of borehole wall and cleats, and analyzing the stress state of borehole wall rock and cleats wall, the breakdown pressure calculation model for CBM open hole completion hydraulic fracturing was established basing on elastic mechanics and fracture mechanics.

2. The damage modes of the coalbed borehole wall have five kinds: fractures initiate from coal rock body, tensile failure along with face cleats, shear failure along with face cleats, tensile failure along with butt cleats and shear failure along with butt cleats. Using the model established in the paper, the breakdown pressure can be obtained and the damage model can be distinguished.

3. According to example calculation, the calculated result using the breakdown pressure calculating model agrees with the actual results. The breakdown pressure calculating model for CBM open hole completion hydraulic fracturing has good applicability.

4. With the increasing of horizontal inclination angle of the face and butt cleats, the breakdown pressure decreases when the rupture is caused by tension failure and shear failure along with face cleats and butt cleats. When the horizontal inclination angle is $0^{\circ}$, the breakdown press is maximum.

5. The effects of adhesion on breakdown pressure is not significant. The change of internal friction coefficient has great effects on breakdown pressure. With the increasing of internal friction coefficient, the breakdown pressure increases significantly when the rupture is caused by shear failure.

\section{NOMENCLATURE}

$\sigma_{\mathrm{r}}$ is the radial stress in borehole area, $\mathrm{MPa}$;

$\sigma_{\theta}$ is circumferential stress, $\mathrm{MPa}$;

$\sigma_{\mathrm{z}}$ is the vertical stress, $\mathrm{MPa}$;

$\tau_{\mathrm{r} \theta}, \tau_{\theta \mathrm{z}}$ and $\tau_{\mathrm{rz}}$ are the shear stress, $\mathrm{MPa}$;

$\sigma_{\mathrm{H}}$ is maximum principal stress, $\mathrm{MPa}$;

$\sigma_{\mathrm{h}}$ is minimum principal stress, $\mathrm{MPa}$;

$\sigma_{\mathrm{V}}$ is the overburden stress, $\mathrm{MPa}$;

$r$ is the wellbore polar radius, $\mathrm{m}$;

$r_{\mathrm{w}}$ is the radius of wellbore, $\mathrm{m}$;

$\mu$ is the poisson's ratio, dimensionless variable;

$p_{\mathrm{w}}$ is the fluid pressure in the wellbore, $\mathrm{MPa}$; $\theta$ is the sinistral polar angle between radial direction of any point and maximum principal stress;

$\alpha$ is the Biot factor;

$\Phi$ is the porosity, dimensionless variable;

$p_{\mathrm{p}}$ is the pore pressure, $\mathrm{MPa}$;

$\sigma_{\mathrm{t}}$ is the tensile strength of coal rock, $\mathrm{MPa}$;

$\sigma_{\mathrm{mn}}$ is the normal stress loading on the face cleats, $\mathrm{MPa}$;

$\gamma_{\mathrm{mi}}$ is the included angle between the face normal line of face cleats and the $\mathrm{i}$-th principal stress, $\left({ }^{\circ}\right), i=1,2,3$;

$p_{\mathrm{mzf}}$ is the fluid pressure in the fracture when the face cleats occur tension failure, $\mathrm{MPa}$;

$\tau_{\mathrm{m} 0}$ is the adhesion of the coal body in face cleats, $\mathrm{MPa}$;

$\mu_{\mathrm{m}}$ is the internal friction coefficient in face cleats, dimensionless variable;

$\sigma_{\mathrm{dn}}$ is the normal stress loading on butt cleats, $\mathrm{MPa}$;

$\gamma_{d \mathrm{i}}$ is the included angle between the face normal line of butt cleats and the $\mathrm{i}$-th principal stress, $\left({ }^{\circ}\right), i=1,2,3$;

$p_{\mathrm{dzf}}$ is the fluid pressure in the fracture when the butt cleats occur tension failure, $\mathrm{MPa}$;

$\tau_{\mathrm{d} 0}$ is the adhesion of the coal body in butt cleats, MPa;

$\mu_{\mathrm{d}}$ is the internal friction coefficient in butt cleats, dimensionless variable;

$p_{\mathrm{f}}$ is the breakdown pressure in open hole completion hydraulic fracturing, $\mathrm{MPa}$;

$p_{\text {bf }}$ is the breakdown pressure when the failure origins from the coal body, MPa;

$p_{\text {mjf }}$ is the breakdown pressure when the breakdown is caused by the shear failure along with face cleats, $\mathrm{MPa}$;

$p_{\mathrm{djf}}$ is the breakdown pressure when the breakdown is caused by the shear failure along with butt cleats, $\mathrm{MPa}$.

\section{CONFLICT OF INTEREST}

The authors confirm that this article content has no conflict of interest.

\section{ACKNOWLEDGEMENTS}

The support of National Natural Science Fund of China (No.51274067) is gratefully acknowledged.

\section{REFERENCES}

[1] Fallahzadeh, S.H.; Shadizadeh, S.R.; Pourafshary, P. Dealing with the challenges of hydraulic fracture initiation in deviated-cased perforated boreholes. SPE 132797, 2010.

[2] Haimson, B.; Fairhurst, C. Initiation and extension of hydraulic fractures in rocks. SPE J., 1967, 7(3), 310-318.

[3] Yew, C.H.; Li, Y. Fracturing of a deviated well. SPE 16930, 1987.

[4] Hossain, M.M.; Rahman, M.K. Hydraulic fracture initiation and propagation: roles of wellbore trajectory, perforation and stress regimes. J. Pet. Sci. Eng., 2000, 27(3), 129-149.

[5] Jin, Y.; Zhang, X.; Chen, M. Initiation pressure models for hydraulic fracturing of vertical wells in naturally fractured formation. Acta Petrol. Sin., 2005, 26(6), 113-124. 
[6] Jin, Y.; Chen, M.; Zhang, X. Hydraulic fracturing Initiation pressure models for directional wells in naturally fractured formation. Acta Petrol. Sin., 2006, 27(5), 124-126.

[7] Zhao, J.; Ren, L.; Hu, Y. Wang, L. A calculation model of breakdown pressure for perforated wells in fractured formations. Acta Petrol. Sin. 2012, 33(5), 841-845.

[8] Zhao, J.; Ren, L.; Hu, Y.; Li, N. Hydraulic fracture tensile initiation pressure analysis for fractured formations. Chin. J. Rock Mech. Eng., 2013, 32(Supp.1), 2855-2862.

[9] Ren, L.; Zhao, J.; Hu, Y.; Wang, L. Tensile initiation characteristics analysis of hydraulic fracture in perforated well of fractured formations. J. Central South Uni. Sci. Technol., 2013, 44(2), 707-713.

[10] Tang, S.; Zhu, B.; Yan, Z. Effect of crustal stress on hydraulic fracturing in coalbed methane wells. J. China Coal Soc., 2011 , 36(1), 65-69.

[11] Chen, M.; Jin, Y.; Zhang, G. Rock Mech. Petrol. Eng., Science Press: Beijing, 2008

[12] Jaeger, J.C.; Cook, N.G.W.; Zimmerman, R.W. Fund. Rock Mech., Blackwell Publishing: Oxford, 2007.

(C) Yuwei et al.; Licensee Bentham Open.

This is an open access article licensed under the terms of the Creative Commons Attribution Non-Commercial License (http://creativecommons.org/licenses/by-nc/3.0/) which permits unrestricted, non-commercial use, distribution and reproduction in any medium, provided the work is properly cited. 